\section{INDIGENISMO Y MIGRACIONISMO. ASPECTOS DE LA NEOLITIZACIÓN EN LA FACHADA ORIENTAL DE LA PENÍNSULA IBÉRICA}

\author{
INDIGENISM AND MIGRATIONISM. \\ ASPECTS OF THE NEOLITIZATION IN \\ THE EAST OF THE IBERIAN PENINSULA
}

JOAN BERNABEU AUBÁN (*)

\section{RESUMEN}

Este trabajo trata algunos aspectos relativos al origen del Neolítico en la Península Ibérica. En el mismo se propone el modelo dual como alternativa a la dicotomía entre las posturas que asumen puntos de vista basados en el movimiento de personas (migracionistas) o de ideas/bienes (indigenistas). Su aplicación a la fachada oriental del Mediterráneo español permite evaluar sus posibilidades, apostando por una mayor complejidad y una lectura territorial del proceso de neolitización.

\begin{abstract}
This paper discusses various aspects on the origins of the Neolithic in the Iberian Peninsula. The dual model is proposed as an alternative to the dichotomy of demic (migrationist) and non-demic (indigenist) explanations. The application of this model in eastern Spain offers an opportunity to evaluate its potential to account for diversity in processes associated with the origins of food production and their spatial organisation.
\end{abstract}

(*) Departament de Prehistòria i Arqueología. Universitat de València. Blasco Ibáñez, 28. 46010 València.

El artículo fue remitido en su versión final el 7-IV-96.
Palabras clave: Neolítico. Expansión agrícola. Mediterráneo español. Modelos de difusión démica y no démica. Modelo Dual.

Key words: Neolithic. Agricultural expansion. Mediterranean Spain. Demic and non-demic diffusion. Dual Model.

\section{PRESENTACIÓN}

En el último decenio el debate sobre los orígenes del Neolítico ha venido centrándose en torno al papel de los movimientos de población, al modo de los descritos en el modelo del frente de avance (Ammerman y Cavalli-Sforza, 1984).

Aun a riesgo de simplificar en exceso, podría considerarse que los puntos de vista se han polarizado entre lo que denominaré migracionistas e indigenistas (Chapman, 1994: 134), de manera que:

- Los indigenistas suponen que el origen de la subsistencia neolítica tuvo lugar a través de los mecanismos de intercambio y/o de las redes sociales existentes entre los grupos mesolíticos del continente europeo, sin necesidad de recurrir a movimientos de población; o suponiendo un papel mínimo de los mismos (por 
ejemplo, Zvelebil y Rowley-Conwy, 1984; Chapman, 1994; Runnel y van Andels, 1988).

- Los migracionistas, por el contrario, ven el proceso como una expansión del poblamiento, de acuerdo con el modelo del frente de avance. Tampoco se ignora en este caso el papel de los grupos mesolíticos en la transmisión de las novedades neolíticas, pero tiende a minimizarse (por ejemplo, Gallay, 1989).

En ambos casos, la amplitud e intensidad del movimiento colonizador simplemente constituye una premisa, lo que en ocasiones lleva a tener que argumentar en contra de la información disponible (veáse Chapman, 1994, frente a Perlès, 1995, en relación al sudeste de Europa).

Esta situación tiene también su traducción en la Península Ibérica, como ponen de relieve algunas de las propuestas más recientes (Mestres, 1991; Vicent, 1990 y 1996; Rodríguez Alcalde et alii, 1995; Schuhmacher y Weniger, 1995).

Aunque en general se tiene la impresión de que ambas posiciones se postulan como mutuamente excluyentes, lo cierto es que, salvo que se considere que los procesos de difusión se realizan siempre con ausencia de movimientos de población o, alternativamente, sobre regiones deshabitadas, ambos forman parte de una dinámica histórica común y son, lógica y empíricamente complementarias. Algunas propuestas intentan justamente una aproximación de estas características, dotando de mayor complejidad el concepto de frontera agrícola (Moore, 1985; Dennell, 1985).

Lo que esta petición de mayor complejidad lleva implícito es que probablemente la situación fue regionalmente diversa. Ello equivale a desautorizar cualquier modelo que se limite a asumir una u otra posición, obligando a afrontar este asunto en concordancia con la evidencia empírica regional. Por tanto, resulta crucial disponer de un modelo que permita acercar las teorizaciones a los hechos. La propuesta del modelo dual pretende incidir en este aspecto trasladando la cuestión del alcance de la colonización agrícola desde el campo de las asunciones, al de la contrastación. Es decir, afirmando que las propuestas en esta materia no sólo deben, sino que pueden ser contrastadas sobre el registro arqueológico regional.
El objetivo de este trabajo consistirá, primero, en presentar el modelo, sus implicaciones empíricas y algunas de las asunciones sobre las que se sustenta (apartados 2 y 3 ). A continuación, se procederá a su contrastación utilizando para ello la información que proporciona la región mediterránea española (apartado 4), investigando también las alternativas propuestas y los problemas que plantean (apartado 5). Finalmente, el apartado 6 incidirá en la valoración de los resultados.

A lo largo de la exposición y a fin de mantener una mínima coherencia, todas las fechas C-14 utilizadas, así como las referencias cronológicas, lo serán en cronología antes del presente, sin calibrar, utilizando las siglas BP. De igual modo, todas las referencias geográficas de los asentamientos utilizados se recogen en el Cuadro 1, evitando su cita repetitiva en el texto.

\section{EL MODELO DUAL}

El modelo dual, en su estructuración más reciente (Bernabeu et alii, 1993), surge de la confluencia de dos corrientes de investigación.

A. Por una parte, de las consecuencias del modelo de "frente de avance" o expansión démica. De acuerdo con la propuesta de la expansión mixta, podrían diferenciarse tres situaciones que caracterizarán otros tantos procesos de difusión:

1. La expansión démica propiamente dicha, o proceso de colonización agrícola. Denominaremos este proceso "Colonización". Diversas regiones fueron colonizadas de este modo. $\mathrm{Re}$ sulta necesario admitir que este proceso se mantuvo vigente más allá de la aparición de las primeras plantas y animales domésticos, como ocurre, por ejemplo, con la colonización agrícola del valle alto del Guadalquivir (Nocete, 1989: 146).

2. La interacción entre los agricultores en expansión y las poblaciones mesolíticas preexistentes. Denominaremos este proceso “Aculturación Directa". Tales procesos se dieron en las fronteras entre ambos grupos, y pueden considerarse como el detonante que inició el proceso posterior, descrito a continuación.

T. P., 53, n. ${ }^{\circ} 2,1996$ 
3. La difusión, entre los grupos mesolíticos, y a través de sus mecanismos de interacción, de los elementos técnicos y económicos neolíticos. Denominaremos este proceso "Aculturación Indirecta".

Los tres son igualmente posibles; sin embargo, sus consecuencias sobre el registro serán distintas en cada caso. Por tanto, si queremos contrastar, a nivel regional, la presencia de tal o cual proceso neolitizador, necesitaremos desarrollar previamente un modelo capaz de explicitar dichas consecuencias. Y es aquí donde se enlaza con la segunda de las corrientes de investigación de las que se nutre el modelo.

B. Esta corriente es básicamente empírica. Tiene que ver con la investigación del fenómeno neolitizador en tierras valencianas y es anterior, en su formulación, al planteamiento del modelo de avance.

Aunque sería posible rastrear sus orígenes con anterioridad, el trabajo de Fortea (1973) marca el punto de inflexión respecto a la interpretación del registro valenciano en el momento de la neolitización. Este autor, al analizar distintas series líticas situadas entre el VIII y VII milenios BP, establece el modelo de la triple facies:

- La facies geométrica, ejemplificada por Cocina, en la que el sustrato epipaleolítico precerámico (Cocina I y II) recibiría las primeras influencias neolíticas (cerámica, Cocina III) sin apenas cambios en su estructura tecno económica, continuando con posterioridad su evolución hasta la incorporación de los recursos domésticos (Cocina IV).

- La facies microlaminar, ejemplificada por Mallaetes, y que vendría a representar la perduración de la tradición microlaminar que entraría en contacto con las cerámicas cardiales.

- La facies neolítica, ejemplificada por Or, cuyo conjunto industrial no sería reductible a ninguno de los anteriores.

En la interpretación de Fortea, la facies de Or representaría el auténtico Neolítico, o neolítico "puro", tal y como ha pasado a la literatura científica posterior; mientras que la facies Cocina vendría a representar la progresiva neolitización del sustrato geométrico a partir de las influencias de la facies Or.

La posterior investigación demostró que las industrias microlaminares de la facies Mallaetes no entraban en contacto con la cerámica (Aura y Pérez Ripoll, 1995).

Por contra, la facies Cocina queda ampliamente corroborada con la aparición de nuevos yacimientos en diferentes puntos del Mediterráneo peninsular, que confirman la secuencia de Cocina (Barandiarán y Cava, 1992; Aura y Pérez Ripoll, 1995).

Como consecuencia, la propuesta inicial de la triple facies quedaba reducida a la doble facies (Geométrico-Neolítico), manteniendo en lo demás los dos supuestos básicos del trabajo de Fortea (Fortea et alii, 1987a; Martí et alii, 1987), a saber:

- Que la fase cerámica Cocina III es equiparable cronológicamente a las fases más antiguas de Or que, a su vez, corresponden a las primeras etapas cerámicas en la Península Ibérica.

- Que ambas facies no son reductibles entre sí ni desde el punto de vista económico ni desde el tecnológico (Juan Cabanilles, 1984, 1985, 1990 y 1992; Fortea et alii, 1987b; Martí, 1980; Martí et alii, 1987; Pérez Ripoll, 1992).

Como consecuencia, las diferencias observadas entre ambas se interpretaron como el resultado de una dualidad cultural durante los períodos iniciales del Neolítico en la región central del Mediterráneo español.

Las propuestas más recientes (Bernabeu y Martí, 1992; Bernabeu et alii, 1993; Bernabeu y Juan Cabanilles, e.p.), estructuran definitivamente este marco interpretativo, implementando las consecuencias de contrastación que se derivarían del mismo.

De este modo, el modelo de la doble facies se convierte en el modelo dual, el definido anteriormente como aculturación directa.

Básicamente, el modelo dual trata de establecer la estructura del registro en una hipotética región donde se produzca una interacción entre los grupos colonizadores neolíticos y los representantes del Mesolítico final regional. Definida esta situación, podremos también caracterizar cuál debiera ser la estructura del registro para los procesos derivados de la colonización o la aculturación indirecta. Para ello se utilizan tres variables: tecnología, subsistencia y asentamiento. 


\section{IMPLICACIONES EMPÍRICAS Y ASUNCIONES}

Comoquiera que la expansión del Neolítico en Europa conlleva la aparición simultánea de rasgos económicos y técnicos (cerámica), el modelo toma como punto de partida las etapas inmediatamente precerámicas de una región para ordenar cronológicamente el registro en tres fases. Sus características han sido descritas ampliamente en otras ocasiones (Bernabeu et alii, 1993) por lo que las enumeraremos sucintamente.

FASE 0. Corresponde a las etapas inmediatamente precerámicas. La subsistencia, tecnología y asentamiento de esta fase definirán un sistema (B0) que se toma como referencia para su comparación con los presentes durante la fase 1.

FASE 1. Su inicio coincide con la aparición de la cerámica. Su duración es variable y, por tanto, puede ser objeto de subdivisiones. Durante esta fase será posible definir en el registro dos sistemas que, por tanto, son homotaxiales.

A1. Sistema caracterizado por la ruptura ocupacional, tecnológica y de subsistencia con respecto a los definidos en la Fase 0.

- Ruptura ocupacional. Manifestada a través de la ocupación de asentamientos no utilizados durante la Fase 0.

- Ruptura tecnológica. Su cultura material presentará fuertes contrastes con la de los grupos mesolíticos de la Fase 0 y, en gran medida, no podrá hacerse derivar de aquélla.

- Ruptura económica. Como corresponde a la suposición de que nos encontramos ante los asentamientos representativos del Neolítico en expansión, su subsistencia se caracterizará por el predominio de la economía mixta agrícola y ganadera.

B1. Sistema caracterizado por su continuidad ocupacional, tecnológica y de subsistencia con respecto al $\mathrm{B} 0$. Los procesos de interacción con los asentamientos del grupo A1 producirán ciertas modificaciones, más visibles en unos apartados que en otros.

- Continuidad ocupacional. Manifestada a través de la ocupación de los mismos asentamientos que ya estaban habitados durante la Fase 0.

T. P., 53, n. ${ }^{\circ} 2,1996$
- Continuidad tecnológica. Su cultura material presentará claras afinidades con la propia del grupo B0. Como resultado de la interacción, podrán incorporar algunas de las novedades tecnológicas características de los sistemas A1, en especial la cerámica.

- Continuidad económica. Su subsistencia seguirá siendo, en gran medida, similar a la tradicional durante el Mesolítico (Fase 0). La incorporación de los nuevos recursos será progresiva (ver más adelante).

FASE 2. Corresponderá con el momento en que ya no sea visible en el registro la dualidad del sistema de subsistencia descrita en la Fase 1.

Las asunciones sobre las que reposa el modelo son las siguientes:

1. El sistema A1 es plenamente neolítico; por tanto, deberán constatarse sociedades de agricultores y ganaderos desde las primeras fases cerámicas. En este punto convergen dos series de problemas que han puesto en tela de juicio el modelo: a) definir los horizontes cerámicos más antiguos; y, b) definir el carácter neolítico de estos mismos horizontes.

La secuencia tradicional para el área mediterránea peninsular, y sobre la que se basa el modelo, considera que el horizonte cerámico más antiguo corresponde con el Neolítico Cardial (Bernabeu, 1989), cuyas fechas iniciales no sobrepasan el $7000 \mathrm{BP}$.

Sin embargo, desde la publicación del abrigo de Verdelpino (Moure y Fernández Miranda, 1976), algunos yacimientos, situados en el interior mediterráneo y en Andalucía, han proporcionado un conjunto cerámico caracterizado por las decoraciones incisas e impresas no cardiales, con cronologías de pleno VIII milenio BP, generalmente asociado con animales domésticos, en especial ovicaprinos.

No pretendo discutir ahora sobre los problemas de índole tafonómica (Fortea y Martí, 1985; Zilhao, 1992), ni los derivados de la estratigrafía comparada entre éstos y otros yacimientos de las mismas regiones con equipamiento material similar y cronología más baja (Bernabeu, 1989). Tan sólo señalaré que las dataciones anteriores al $7000 \mathrm{BP}$, son incongruentes con una hipótesis suficientemente contrastada: la ausencia de antecedentes silvestres para las especies domésticas más importantes de nuestro Neolítico (ovi- 
caprinos, cereales, legumbres). Si ello es así, la presencia de animales domésticos en cualquier contexto debe explicarse desde el supuesto de su disponibilidad. Y, dado que en el Mediterráneo occidental las dataciones más antiguas sitúan el inicio de la neolitización en torno al 7500 $\mathrm{BP}$ en el área adriática y del $7000 \mathrm{BP}$ en lo franco-ibérico, la aceptación de aquellos contextos necesariamente obligaría a considerar la domesticación local al menos de los ovicápridos, lo que no puede sostenerse.

Pero, aun aceptando la premisa de que el Cardial constituye el horizonte cerámico más antiguo, todavía subsiste otro problema: demostrar que este horizonte asocia también un modo de vida plenamente neolítico. Aunque este asunto se retomará más adelante (apartado 5), convendrá clarificar qué se entiende por "modo de vida neolítico". Teniendo en cuenta el contexto histórico que nos ocupa, las variables significativas a considerar en este caso son:

- La cerealicultura mixta. Sistema de subsistencia especializado, de rendimiento aplazado, basado en la plena dependencia de los recursos domésticos, tanto agrícolas (cereales + legumbres), como ganaderos (ovicápridos, suidos y bóvidos).

- La vida aldeana. Organización del territorio basada en la existencia de asentamientos (poblados) estables, entendiendo por estabilidad la ausencia de ciclos estacionales de agregación/dispersión.

Como consecuencia, deberíamos encontrar grupos de trabajo estables (lo que comúnmente se denomina Comunidades Domésticas), con el equipamiento necesario para explotar, de forma autónoma, la tierra liberada al saltus, el ager, utilizando un símil latino que viene perfectamente al caso. Ligadas al producto almacenado, estas comunidades domésticas no necesitan de grandes inversiones para poner en producción la tierra, razón por la cual les resultará igualmente fácil abandonarla para buscar nuevos predios donde instalarse. La segmentación, por tanto, será una característica de estos grupos sociales, al menos hasta tanto no se encuentren límites a la misma (mientras sea posible proseguir la colonización sin entrar en conflicto con otros grupos, o sin que se perciba como una disminución del nivel de vida en el interior del grupo).
Sólo desde este punto de vista podría decirse que estos "agricultores primitivos", a diferencia de los campesinos, no se encuentran ligados a los medios de producción. Considero que esta característica no mide la distancia entre modos de vida neolíticos y no neolíticos, sino entre agricultores y campesinos. Los primeros son el resultado inmediato de la Revolución Neolítica, los últimos, su consecuencia aplazada, aunque no inevitable (1).

2. Los asentamientos de los sistemas B1 y A1 son contemporáneos.

3. El conjunto de asentamientos incluidos en B1 no representa una especialización funcional y/o estacional con respecto al conjunto incluido en A1.

4. Dada la suposición de que los asentamientos A1 se generan por colonización, vía expansión demográfica, es de esperar que exista entre ellos un cierto grado de uniformidad en su equipamiento material. Consecuentemente, cabe suponer que las primeras fases cerámicas constituyan horizontes cronoculturales homogéneos en territorios extensos.

La contrastación de este punto siempre puede ser discutible, pero el análisis de ciertas variables cerámicas (técnicas decorativas), realizado en otra ocasión (Bernabeu, 1989) demostró que, en el conjunto de lo franco-ibérico, las primeras fases cerámicas, dominadas por el binomio decoración cardial+relieves, constituían un auténtico horizonte cultural interregional, cuya fragmentación resulta visible a partir de $c a .6400 \mathrm{BP}$, con la irrupción de los estilos epicardiales.

5. A una escala regional convenientemente amplia el modelo dual será el único visible. La razón de ello reside en que cuanto mayor sea el área analizada tanto mayor será la probabili-

(1) Tomo prestada esta diferenciación, ampliándola, de Wolf (1971: 12) quien define a los campesinos como “... labradores y ganaderos rurales cuyos excedentes son transferidos a un grupo dominante...". Considero, por tanto, que la mayor inversión en la tierra (como también en la estructuración interna del hábitat) se encuentra relacionada con una complejidad (jerarquización) social también creciente, lo que produce una mayor circunscripción social y conlleva una mayor dificultad para abandonar el grupo. A menudo, los diferentes sistemas neolíticos presentan notables diferencias en lo que se refiere a esta característica, razón por la cual no creo que pueda utilizarse para definirlos. 
dad de que se incluyan procesos diversos. Y, cualquier combinación entre los procesos descritos, dará siempre una imagen similar a la "aculturación directa".

\section{LA REGIÓN MEDITERRÁNEA PENINSULAR}

La fachada oriental del Mediterráneo español, desde los Pirineos al Segura, y desde las regiones costeras al interior montañoso que bordea la Meseta, constituye una región diversa, aunque dominada por los pisos bioclimáticos termomediterráneo y mesomediterráneo. La documentación disponible es, pese a sus limitaciones, mayor que en cualquier otra región peninsular, lo que proporciona el marco adecuado para la contrastación de la hipótesis dual.

A. Secuencia regional. El sustrato epipaleolítico precerámico es suficientemente conocido, caracterizándose por el desarrollo de las industrias geométricas tipo Cocina, que denominaremos Complejo Geométrico. Diversas estratigrafías ejemplifican su evolución, que podría resumirse como el resultado del predominio alternante de las diferentes formas geométricas (trapecios, triángulos y segmentos). Junto a ello, la disminución progresiva de la técnica del microburil y del retoque abrupto, y el aumento del retoque en doble bisel, perfilan la secuencia. Sobre esta base se ha propuesto una evolución en cuatro horizontes, denominados con las letras A, B, C y D (Fortea, 1973; Juan Cabanilles, 1990).

Recientemente, Miró (e.p.), señala que los conjuntos caracterizados por el binomio segmentos+doble bisel derivan de la tradición geométrica, incorporando ya los elementos característicos del Complejo Neolítico. De ser cierta, esta hipótesis alargaría la secuencia del Complejo Geométrico más allá de la mitad del VI milenio BP, momento en el que los trabajos antes citados situaban el final de este complejo.

Entre los horizontes B y C del Complejo Geométrico, la secuencia tradicional sitúa la aparición del Complejo Neolítico cuyas primeras manifestaciones se acompañan por las ya clásicas cerámicas cardiales y un sistema de subsistencia basado en la agricultura y ganadería. Las características de su industria lítica po- drían resumirse en las siguientes (Juan Cabanilles, 1984 y 1990; Fortea et alii, 1987b):

- Elevada proporción de útiles no retocados, especialmente hojas y hojitas con señales de utilización.

- Dentro del utillaje retocado, predominio de las hojas y hojitas retoçadas.

- Geometrismo dominado por las formas trapezoidales mayoritariamente conformadas mediante el retoque abrupto.

Estas características básicas parecen mantenerse a lo largo de toda su evolución, incorporando, hacia fines del VI o comienzos del V milenio $\mathrm{BP}$, las puntas de flecha de retoque bifacial.

Con el fin de contrastar esta supuesta estabilidad, así como correlacionarla con los conjuntos derivados del Complejo Geométrico, utilizaremos en el análisis dos colecciones del V milenio BP (Jovades y Arenal de la Costa). De esta forma se incluirán en el mismo diversos conjuntos arqueológicos escalonados entre $c a$. 7500 BP y 4000 BP.

Teniendo en cuenta que nuestro propósito consiste en medir adecuadamente la tecnología y subsistencia (el asentamiento se introducirá más adelante) en los Complejos Geométrico y Neolítico, así como la variabilidad temporal del primero, se han considerado significativas las siguientes variables:

Tr = proporción de triángulos dentro del conjunto de los geométricos.

Trp = proporción de trapecios dentro del conjunto de los geométricos.

Seg $=$ proporción de segmentos dentro del conjunto de los geométricos.

Mi = proporción de microburiles (M1 de Fortea) en relación al utillaje retocado.

$\mathbf{D b}=$ proporción de geométricos realizados mediante la técnica del doble bisel.

Ilre $=$ proporción de hojas y hojitas retocadas en relación al utillaje retocado. No se han considerado como tales aquéllas con retoque abrupto conformando un dorso. Aunque suele admitirse (Juan Cabanilles, 1984), que morfológicamente son distintas de las hojitas de dorso epipaleolíticas, su inclusión en este apartado hubiera supuesto introducir un criterio de apreciación subjetiva no

T. P., 53, n. ${ }^{\circ} 2,1996$ 


\begin{tabular}{|c|c|c|c|c|c|c|c|c|c|c|c|c|c|c|}
\hline Yacimiento & Nivel & $\operatorname{Tr}$ & $\operatorname{Trp}$ & Seg & Mi & Ilre & Grupos & Dom & $\mathrm{Db}$ & T.Util. & T.Geo. & Fact.1 & Fact. 2 & C-14 BP \\
\hline \multirow[t]{2}{*}{ 20. Tossal de la Roca, abrigo (Alicante) } & S & 0,15 & 0,85 & 0 & 0,02 & 0,09 & G1 & 0 & 0 & 54 & 8 & $-0,18$ & $-1,08$ & (Cacho, 1988) \\
\hline & 1 & 0,07 & 0,93 & 0 & 0 & 0,03 & G1 & 0 & 0 & 84 & 15 & $-0,14$ & $-1,26$ & $7660 \pm 80 ; 7560 \pm 80$ \\
\hline 21. La Falguera, abrigo (Alicante) & 1 & 0 & 1 & 0 & 0 & 0,06 & G1 & 0 & 0,14 & 66 & 7 & 0,07 & $-1,22$ & $\begin{array}{l}7410 \pm 70 \text {; inédito. Para la fecha } \\
\text { (Barton et alii, 1990) }\end{array}$ \\
\hline 15. Cocina, cueva (Valencia) & & 0,02 & 0,98 & 0 & 0,03 & 0,01 & G1 & 0 & 0 & 116 & 47 & $-0,21$ & $-1,37$ & (Fortea, 1971 y 1973 ) \\
\hline \multirow[t]{2}{*}{ 7. Costalena, abrigo (Zaragoza) } & $d$ & 0,33 & 0,67 & 0 & 0,05 & 0,05 & $\mathrm{G} 2$ & 0 & 0 & 72 & 3 & $-0,67$ & $-0,73$ & (Barandiarán y Cava, 1989) \\
\hline & c.3 3 & 0,21 & 0,79 & 0 & 0,16 & 0,03 & $\mathrm{G} 2$ & 0 & 0,01 & 539 & 86 & $-0,89$ & $-0,98$ & $6420 \pm 250$ (tramo superior) \\
\hline 9. Botiquería, abrigo (Teruel) & 2 & 0,15 & 0,85 . & 0 & 0,1 & 0,03 & $\mathrm{G} 2$ & 0 & 0,01 & 292 & 21 & $-0,6$ & $-1,1$ & $7550 \pm 200$ (Barandiarán, 1978). \\
\hline Botiqueria & 6 & 0,59 & 0,27 & 0,14 & 0,01 & 0,04 & G4 & 0 & 0,62 & 85 & 22 & $-0,86$ & 0,93 & \\
\hline Costalena & c. 2 & 0,68 & 0,2 & 0,12 & 0,06 & 0,04 & G4 & 0 & 0,51 & 275 & 55 & $-1,19$ & 0,92 & \\
\hline Costalena & c. $2-1, \mathrm{~b}$ & 0,41 & 0,27 & 0,23 & 0,02 & 0,05 & G4 & 0 & 0,59 & 104 & 22 & $-0,6$ & 0,87 & \\
\hline Costalena & c. $3-2$ & 0,39 & 0,43 & 0,13 & 0,05 & 0,04 & G4 & 0 & 0,39 & 154 & 23 & $-0,73$ & 0,27 & \\
\hline Botiquería & 4 & 0,6 & 0,4 & 0 & 0,1 & 0,02 & G3 & 0 & 0,19 & 106 & 67 & $-1,31$ & 0,04 & \\
\hline Cocina & 2 & 0,62 & 0,34 & 0,04 & 0,39 & 0,01 & G3 & 0 & 0 & 172 & 53 & $-2,36$ & 0,07 & \\
\hline Cocina & 3 & 0,41 & 0,12 & 0,47 & 0,13 & 0,01 & G4 & 0,02 & 0 & 39 & 17 & $-1,07$ & 0,98 & \\
\hline 22. Nacimiento, cueva (Jaén) & 2 & 0,31 & 0,46 & 0,23 & 0,07 & 0,12 & G5 & 0,37 & 0,15 & 32 & 8 & $-0,1$ & 0,15 & $\begin{array}{l}5490 \pm 120 \text { (Asquerino y López, } \\
1981 \text { ) }\end{array}$ \\
\hline 14. Verdelpino, abrigo (Cuenca) & $2-3$ & 0,17 & 0,17 & 0,66 & 0,03 & 0,12 & G6 & 0,52 & 0,83 & 59 & 6 & 0,42 & 1,24 & $\begin{array}{l}4810 \pm 130 \text { (Moure y Fernández } \\
\text { Miranda, 1976) }\end{array}$ \\
\hline Cocina & 4 & 0,22 & 0,33 & 0,44 & 0,07 & 0,15 & G5 & 0,55 & 0,11 & 41 & 9 & 0,23 & 0,53 & \\
\hline 17. Sarsa, cueva (Valencia) & & 0 & 1 & 0 & 0 & 0,29 & G8 & 0,66 & 0,2 & 78 & 5 & 1,21 & $-0,92$ & (Juan Cabanilles, 1984) \\
\hline 5. Chaves, cueva (Huesca) & IIab & 0,14 & 0,57 & 0,28 & 0 & 0,14 & G7 & 0,7 & 0,43 & 74 & 7 & 0,71 & 0,36 & $\begin{array}{l}\text { Ilb: } 4820 \pm 70 ; 4.700 \pm 80 ; 4.510 \pm 70 \\
3260 \pm 340 \\
\text { IIa: } 4280 \pm 70 ; 4170 \pm 70 \\
\text { (Baldellou y Utrilla, } 1985 \text { ) }\end{array}$ \\
\hline 18. Or, cueva (Alicante) & III & 0,02 & 0,8 & 0,13 & 0,01 & 0,29 & G8 & 0,74 & 0,06 & 823 & 171 & 1.2 & $-0,62$ & $\begin{array}{l}\text { N.III:4770 } \pm 380 ; 4680 \pm 290 \\
\text { (Bernabeu, 1989) } \\
\text { N.II: } 4030 \pm 260 ; \text { S.R: } 4650 \pm 160 \text {; } \\
4315 \pm 75\end{array}$ \\
\hline 3. Les Guixeres (Barcelona) & NAE & 0 & 0,43 & 0,28 & 0,01 & 0,39 & G7 & 0,75 & 0,14 & 100 & 7 & 1,45 & 0,16 & (Mestres, 1987) \\
\hline Les Guixeres & NAC & 0,17 & 0,79 & 0,04 & 0 & 0,19 & G7 & 0,75 & 0,43 & 224 & 23 & 0,8 & $-0,21$ & \\
\hline 1. Plansallosa (Girona) & & 0 & 1 & 0 & 0,01 & 0,17 & G8 & 0,76 & 0 & 42 & 2 & 0,92 & $-1,18$ & $5890 \pm 80$ (Bosch, 1994) \\
\hline 2. La Draga (Girona) & & 0 & 0,8 & 0,2 & 0 & 0,41 & G8 & 0,81 & 0 & 82 & 5 & 1,65 & $-0,55$ & (Bosch, 1992) \\
\hline 4. Timba del Bareny (Tarragona) & & 0,13 & 0,23 & 0,59 & 0 & 0,34 & G6 & 0,81 & 0,55 & 545 & 39 & 1,38 & 1,46 & $\begin{array}{l}5240 \pm 160 \text { (Miró, com. per.; } \\
\text { Miró et alii, 1992) }\end{array}$ \\
\hline 19. Jovades (Alicante) & & 0 & 1 & 0 & 0 & 0,19 & G8 & 0,82 & 0 & 632 & 5 & 1,06 & $-1,16$ & $\begin{array}{l}4810 \pm 60 ; 4660 \pm 90 ; 4370 \pm 60 \text { (Ber- } \\
\text { nabeu, dir, 1993) }\end{array}$ \\
\hline 16. Arenal de la Costa (Valencia) & & 0,25 & 0 & 0,75 & 0 & 0,2 & G6 & 0,91 & 1 & 161 & 4 & 1,02 & 2,58 & $3890 \pm 90$ (Bernabeu, dir, 1993) \\
\hline 6. Riols I (Zaragoza) & & 0,85 & 0,13 & 0,02 & 0,01 & 0,29 & • & • & - & - & - & - & $\bullet$ & $\begin{array}{l}6040 \pm 100 \text { (G.4 o G.5) (Royo } \\
\text { y Gómez, 1992). }\end{array}$ \\
\hline 11. Can Ballester, abrigo (Castellón) & 4 & 0,25 & 0,5 & 0,25 & 0,01 & 0,01 & - & • & • & 168 & 24 & - & - & $\begin{array}{l}6950 \pm 120 \text { (G.4) (Gusi y Olaria, } \\
\text { 1979). }\end{array}$ \\
\hline 13. Llatas, covacha (Valencia) & 1,2 & 0.4 & 0,5 & 0,36 & 0 & 0,05 & - & - & 0,23 & 103 & 56 & - & - & (Fortea, 1973); G.5 \\
\hline Can Ballester & 3 & 0,43 & 0,27 & 0,3 & 0,01 & 0,01 & - & - & $\bullet$ & - & - & - & - & \\
\hline Can Ballester & 5 & 0,75 & 0,25 & 0 & 0,03 & 0 & - & • & - & 32 & 4 & - & - & \\
\hline 10. Alonso Norte (Teruel) & & 0,24 & 0,15 & 0,61 & 0 & 0,08 & - & - & 0,67 & 156 & 33 & - & • & $\begin{array}{l}4600 \pm 160(\mathrm{G} .6) \text { (Benavente y An- } \\
\text { dres, } 1990)\end{array}$ \\
\hline 12. Els Estanys (Castellón) & & 0,45 & 0,45 & 0,05 & 0,05 & 0,04 & - & - & 0,05 & - & 20 & - & - & (Fortea, 1975); G.1-2, G.3 \\
\hline 8. El Pontet, abrigo (Zaragoza) & $\mathrm{e}$ & $\bullet$ & $\bullet$ & - & $\bullet$ & - & - & • & $\bullet$ & - & • & - & - & $\begin{array}{l}7340 \pm 70 \text { G.1-2 (Mazo y Montes, } \\
1992 \text { ) }\end{array}$ \\
\hline El Pontet & c.3 & - & - & - & - & - & - & - & - & • & - & - & - & $6370 \pm 70 ;$ G.4 (c.3, sup.) \\
\hline
\end{tabular}

Cuadro 1. Asentamientos de los complejos Geométrico y Neolítico de la región mediterránea peninsular. En el mismo se indican los valores de las variables originales utilizadas en el análisis (las abreviaturas se explican en el texto, p. 66), el total de útiles líticos y de geométricos, las puntuaciones factoriales y el grupo al que corresponde cada conjunto. En la columna final se señala la bibliografía y las dataciones C-14.

justificado. Por otro lado, esta variable presenta evidentes problemas para su correcta cuantificación. En aquellas co- lecciones analizadas de acuerdo con la tipología de Fortea suelen incluirse en el tipo D2, aunque sin especificar el so- 
porte. En razón de ello, y salvo que exista información adicional, se ha adoptado el criterio de contabilizar como hojas/hojitas retocadas el $70 \%$ de los útiles que aparecen en el apartado D2.

Dom = proporción de restos domésticos en relación al total de los restos óseos. Hubiera sido deseable incluir aquí alguna medida relativa a la cuantificación de los recursos agrícolas. Pero, en este caso, los sistemas de muestreo utilizados en las diversas excavaciones hubieran condicionado excesivamente la variabilidad de la muestra.

En el cuadro 1 se detallan los valores de estas variables en aquellos conjuntos arqueológicos sobre los que ha sido posible obtener información. Se advierte inmediatamente que algunos de ellos presentan muestras demasiado escasas, en algún caso inferiores a las 50 evidencias líticas retocadas. Para evitar, o cuando menos conocer, cómo incide el tamaño de las muestras sobre el resultado, plantearemos el análisis a un doble nivel: en primer lugar, considerando solamente aquellas colecciones con

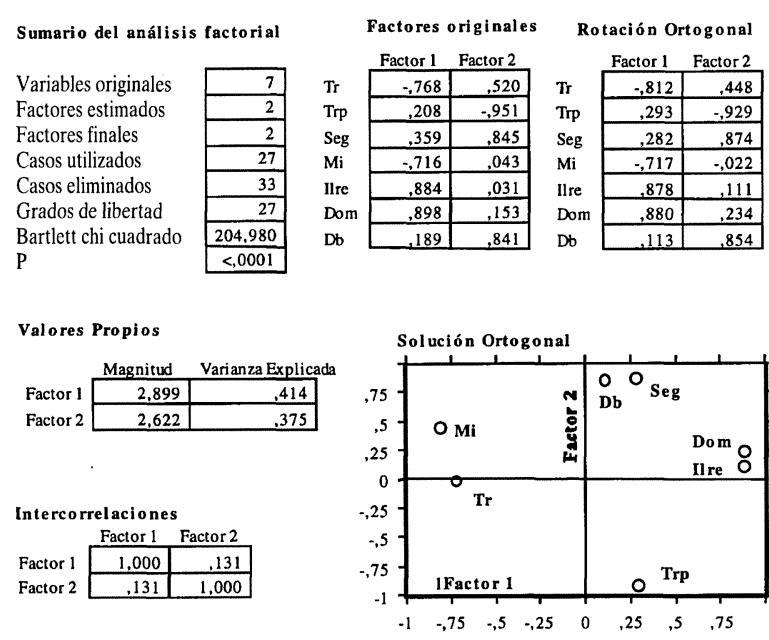

Fig 1. Resultados del análisis factorial. El factor 1 define el carácter técnico y económico de los conjuntos neolíticos a través de la asociación Ilre+Dom, contrapuesta a la que forman $\mathrm{Tr}+\mathrm{Mi}$. El factor 2 contrapone los conjuntos dominados por el geometrismo trapezoidal, frente a los caracterizados por los segmentos realizados con la técnica del doble bisel. $\mathrm{n}>80 \mathrm{y}$, con posterioridad, con el conjunto de las muestras.

B. Resultados del análisis. Planteado en los términos descritos, hemos realizado un análisis factorial de componentes principales. El análisis se realizó mediante el programa Statwiew 5.0 para Macintosh, reteniéndose únicamente aquellos factores con valores propios superiores a 1 . Los resultados iniciales fueron rotados, mediante el procedimiento Varimax, a fin de obtener una matriz factorial donde los coeficientes de saturación de las variables en los factores fueran más fácilmente interpretables.

Las siete variables originales se redujeron a dos factores, con una proporción de varianza explicada del $78,9 \%$. La matriz factorial, una vez rotada ofreció los siguientes resultados (Fig. 1).
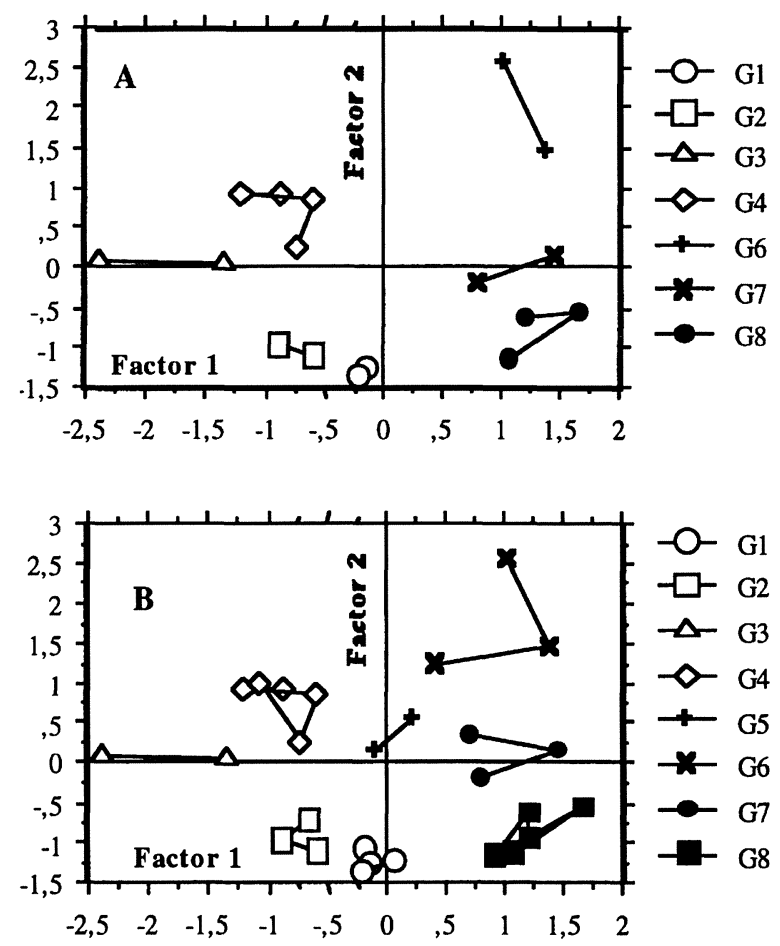

Fig. 2. Diagramas de dispersión de los asentamientos en función de sus puntuaciones factoriales. A) Sólo conjuntos con $\mathrm{n}>80$; B) Todos los conjuntos G.1,2 y 3 corresponden a los asentamientos geométricos precerámicos; G.7 y 8, a los asentamientos de tradición cardial (incluyendo el conjunto de Jovades, $\mathrm{V}$ milenio BP); G5 y 6, definen tradiciones geométricas con cronología cerámica diversa. Sólo G.6 resulta comparable con G.7+8 en las variables Ilre+Dom. 
El factor 1 asocia valores positivos de las variables Ilre+Dom, junto con valores negativos de las variables $\operatorname{Tr}+\mathrm{Mi}$.; el factor 2, asocia valores negativos de las variables Seg $+\mathrm{Db}$, junto con valores positivos de Trp.

Esta estructura sugiere que los asentamientos se organizarán, de acuerdo con la composición de su componente geométrico, a lo largo de eje del factor 2: con valores altos negativos, los definidos por el predominio de trapecios y del retoque abrupto; con valores altos positivos, los caracterizados por el predominio de segmentos y retoque en doble bisel. Con un valor medio (en torno a 0 ) en este factor, pero con valores negativos en el factor 1 se situarán aquellos yacimientos definidos por el predominio de los triángulos y altos valores porcentuales de microburiles. En contraposición, los valores altos positivos en el factor 1 definen el carácter técnico y económico del Complejo Neolítico, caracterizado por la dependencia de los domesticados (Dom) y la producción de hojas y hojitas retocadas (Ilre).

Los gráficos de dispersión de puntos de la figura 2 ilustran esta situación. A partir de éstos se diferenciaron ocho grupos, siete si se consideran solamente las muestras superiores a 80 evidencias líticas retocadas.

Para comprobar el grado de homogeneidad entre estos grupos, se ha realizado un análisis de varianza. Lo que nos interesa, sobre todo, es conocer las diferencias entre cada par de grupos. Para ello se retendrán como heterogeneidades significativas aquéllas con una probabilidad asociada inferior a 0,01 . Los resultados podrían resumirse del siguiente modo (Cuadro 2):

\begin{tabular}{|llllllll|}
\hline & G2 & G3 & G4 & G5 & G6 & G7 & \multicolumn{1}{c|}{ G8 } \\
\hline G1 & HH/HH & hh/hh & Hh/hh & H/h & hh/hh & $\mathrm{hh} / \mathrm{hh}$ & $\mathrm{h} / \mathrm{HH}$ \\
G2 & & $\mathrm{Hh} / \mathrm{Hh}$ & $\mathrm{HH} / \mathrm{hh}$ & $\mathrm{H} / \mathrm{h}$ & $\mathrm{hh} / \mathrm{hh}$ & $\mathrm{hh} / \mathrm{Hh}$ & $\mathrm{hh} / \mathrm{HH}$ \\
$\mathrm{G} 3$ & & & $\mathrm{hh} / \mathrm{HH}$ & $\mathrm{h} / \mathrm{H}$ & $\mathrm{hh} / \mathrm{hh}$ & $\mathrm{hh} / \mathrm{HH}$ & $\mathrm{hh} / \mathrm{Hh}$ \\
G4 & & & & $\mathrm{h} / \mathrm{H}$ & $\mathrm{hh} / \mathrm{hh}$ & $\mathrm{hh} / \mathrm{HH}$ & $\mathrm{hh} / \mathrm{hh}$ \\
G5 & & & & & $\mathrm{h} / \mathrm{h}$ & $\mathrm{h} / \mathrm{HH}$ & $\mathrm{h} / \mathrm{h}$ \\
G6 & & & & & & $\mathrm{HH} / \mathrm{hh}$ & $\mathrm{HH} / \mathrm{hh}$ \\
G7 & & & & & & & $\mathrm{HH} / \mathrm{Hh}$ \\
\hline
\end{tabular}

Cuadro 2. Resultado de la aplicación del test de Fisher PLSD para los Factores 1 y 2 entre los grupos aislados. $\mathrm{H}=$ Homogeneidad; $\mathrm{h}=$ heterogeneidad, al nivel $p<0,01$. A la izquierda los resultados del factor 1 , siendo la primera letra correspondiente a la comparación entre las muestras con $n>80$ útiles retocados.
- A todos los efectos, los grupos G.1 y 2 pueden considerarse homogéneos y sus valores equiparables en los dos factores $(\mathrm{p}<01)$.

- El resto de los grupos muestra rupturas en uno o los dos factores $(\mathrm{p}<01)$, aunque con variaciones según se considere a todos los yacimientos y niveles o sólo aquéllos con $\mathrm{n}>80$. En el primer caso, aparecería diferenciado el G.5, y se separarían los G. 7 y 8 . En el segundo, además de la desaparición de G.5, la comparación entre G.7 y 8 en el factor 2 no permitiría rechazar la hipótesis de homogeneidad entre ambos.

Consecuentemente, los ocho grupos iniciales podrían reestructurarse del siguiente modo: G.1+G.2; G.3; G4; G.6; G.7+G.8. El grupo 5, sólo presente si se incluyen todos los asentamientos, se considerará en relación con el grupo 4 .

Una vez aislados conviene pasar a su definición en términos de las variables originales (Cuadro 3). En la argumentación que sigue introduciremos algunos yacimientos no incluidos en el análisis factorial, de los que sólo se posee información cualitativa o parcial. Todos ellos se relacionan en el cuadro 1.

- G.1 y G.2. Ambos grupos definen un horizonte en el que los trapecios de retoque abrupto son la forma geométrica dominante, siendo el resto de las variables de escasa o nula incidencia. Ambos grupos se corresponden con el horizonte A del Complejo Geométrico. Entre los que no han podido incluirse en el análisis cabría citar a El Pontet, nivel e.

Debe considerarse una apreciación, por lo que respecta al nivel c. 3 de Costalena. Ello es

\begin{tabular}{|llllllll|}
\hline & Tr & Trp & Seg & Db & Mi & Ilre & Dom \\
\hline G1/2 & 0,13 & 0,87 & 0 & 0,02 & 0,05 & 0,04 & 0 \\
& 0,11 & 0,12 & & 0,05 & 0,06 & 0,03 & \\
G3 & 0,61 & 0,37 & 0,02 & 0,1 & 0,25 & 0,02 & 0 \\
& 0,01 & 0,04 & 0,04 & 0,13 & 0,21 & 0,007 & \\
G4 & 0,5 & 0,26 & 0,22 & 0,42 & 0,05 & 0,04 & 0,004 \\
& 0,13 & 0,11 & 0,15 & 0,25 & 0,05 & 0,02 & 0,009 \\
G5 & 0,27 & 0,4 & 0,34 & 0,13 & 0,07 & 0,13 & 0,5 \\
& 0,06 & 0,09 & 0,15 & 0,03 & 0,00 & 0,02 & 0,07 \\
G6 & 0,19 & 0,14 & 0,65 & 0,65 & 0,007 & 0,23 & 0,74 \\
& 0,06 & 0,13 & 0,09 & 0,31 & 0,01 & 0,10 & 0,22 \\
G7/8 & 0,04 & 0,8 & 0,12 & 0,16 & 0,004 & 0,26 & 0,75 \\
& 0,07 & 0,21 & 0,12 & 0,18 & 0,005 & 0,10 & 0,05 \\
\hline
\end{tabular}

Cuadro 3. Media (fila superior) y desviación estándar (fila inferior) de las variables originales para los grupos aislados en el análisis factorial. 
que los tramos superiores del mismo, los 3 y 4 del sondeo de referencia realizado en los cuadros 9L y 9M (Barandiarán y Cava, 1989: 99), deben ponerse en relación con el horizonte $\mathrm{B}$ del Complejo Geométrico (que corresponde al grupo 3). De estos tramos procede la datación C-14 obtenida. Sin embargo, el desglose de los materiales dentro de este nivel no resulta posible a partir de los datos publicados, por lo que el análisis sitúa a c. 3 dentro del grupo 2, mientras que el subnivel superior, trancisión c.3/c.2, donde aparece la primera cerámica (Barandiarán y Cava, 1989: 126) se relaciona ya con el grupo 4. Cinco dataciones pueden referirse a este horizonte.

Tossal de la Roca, nivel I $7560 \pm 80 \mathrm{BP}$ $7660 \pm 80 \mathrm{BP}$

Botiquería, nivel $2 \quad 7550 \pm 200 \mathrm{BP}$ El Pontet, nivel e $\quad 7340 \pm 70 \mathrm{BP}$ La Falguera, $1 \quad 7410 \pm 70 \mathrm{BP}$

- G. 3. Los triángulos se convierten en la forma geométrica dominante y los microburiles adquieren ahora su máxima significación; el resto de las variables tiene escasa relevancia. Estas características se avienen bien con las propias del Horizonte B del Complejo Geométrico. Entre los conjuntos relacionables con este horizonte, pero que no han podido incluirse en el análisis destacan: El Pontet c.2, Can Ballester, 5 y probablemente Els Estanys. Aunque la secuencia tradicional sitúa la aparición de la cerámica dentro del Horizonte C (grupo 4 de nuestro análisis), los datos de El Pontet, donde aparece en los tramos superiores del nivel c.2; y la secuencia de la Falguera, donde el primer nivel cerámico presenta unas más claras afinidades con el Horizonte Cardial, plantean la posibilidad de una aparición escalonada a lo largo de este horizonte. Sólo disponemos de una fecha C-14:

- Costalena c.3, superior $6420 \pm 250$ BP.

- G.4. En su componente geométrico, este grupo está definido por el ligero predominio de los triángulos y la aparición significativa de los segmentos y el doble bisel. Sólo en un caso, Cocina III, se documentan los domésticos, aunque en proporciones irrelevantes. La cerámica se generaliza al conjunto de los asentamientos de la región, estando presentes tanto las decoraciones cardiales como las incisas e impresas no cardiales. Se incluirían también aquí Can Ballester 4 y El Pontet, nivel c.1.

En un momento más avanzado debería situarse el grupo 5. Sus características se sitúan a medio camino entre el grupo 4 y el grupo 6 . Por primera vez, las variables Ilre y Dom. adquieren proporciones significativas.

Además de la cueva del Nacimiento, nivel 2 y Cocina IV podrían incluirse aquí la covacha de Llatas, El Pontet, nivel b; Can Ballester, nivel $3 \mathrm{y}$, de confirmarse las primeras noticias, el poblado de Riols. En todos ellos, su geometrismo se aviene bien con el descrito para el grupo 5; sin embargo, la concordancia es bastante menor en las variables Ilre y Dom. En lo que se refiere a esta última, la ausencia de evidencias (Riols, Costalena, El Pontet), o la falta de estudios sobre las mismas (Can Ballester y Llatas) es determinante. Por otra parte, la ausencia de cerámica cardial abunda en el criterio de mayor modernidad de estos conjuntos con respecto a los incluidos en el grupo 4, lo que se comprueba también con las dataciones $\mathrm{C}-14$ disponibles.

En resumen, aunque la evidencia empírica no permite extraer conclusiones definitivas, sería posible admitir la existencia de un grupo con unas características similares a las del grupo 5, donde comenzase a reflejarse una mayor variabilidad en la aceptación de los componentes neolíticos. Así, mientras en algunos lugares, los cambios son aún escasos, en otros son ya notables e incluso pueden suponer la plena neolitización del sustrato.

Considerados conjuntamente, ambos grupos cubrirían los horizontes $\mathrm{C}$ y D del Complejo Geométrico. Sólo disponemos de cinco dataciones C-14:

$\begin{array}{ll}\text { Can Ballester, } 4 & 6950 \pm 120 \mathrm{BP} \\ \text { El Pontet, c. } & 6370 \pm 70 \mathrm{BP} \\ \text { Riols 1 } & 6040 \pm 100 \mathrm{BP} \\ \text { El Pontet, b } & 5450 \pm 290 \mathrm{BP} \\ \text { Nacimiento 2 } & 5490 \pm 120 \mathrm{BP}\end{array}$

G.6. Este grupo viene definido por el predominio de los segmentos y el retoque en doble bisel. Asimismo, las variables Ilre y Dom. presentan valores comparables a los de los grupos 7 y 8 . El yacimiento de Alonso Norte podría incluirse también aquí.

El G.6 resulta una novedad en el marco de la secuencia tradicional, y vendría a apoyar la su-

T. P., 53, n. ${ }^{\circ} 2,1996$ 
gerencia realizada por Miró (1996), antes comentada. Ello significaría que la tradición industrial geométrica resultaría perceptible bastante después de la plena neolitización del sustrato, como parece indicar el caso de Arenal de la Costa. Disponemos de seis dataciones C-14:

Timba del Bareny $5240 \pm 160 \mathrm{BP}$

Verdelpino $2 \quad 4630 \pm 130 \mathrm{BP}$

Verdelpino $3 \quad 5170 \pm 130 \mathrm{BP}$

$5120 \pm 130 \mathrm{BP}$

Alonso Norte $\quad 4600 \pm 160 \mathrm{BP}$

Arenal de la Costa $3890 \pm 90$ BP

Estas fechas situarían al grupo 6 con un amplio margen cronológico, entre CIRCA 54003800 BP, dentro de la cual se producirán, lógicamente, cambios en otros campos de la cultura material. Así, las fechas más antiguas corresponden a conjuntos cerámicos notablemente uniformes, con decoraciones incisas e impresas casi siempre combinadas sobre los mismos fragmentos. La más reciente, Arenal de la Costa, corresponde al Horizonte Campaniforme.

— G.7 y 8. Las características definitorias de este grupo son: importancia cuantitativa de las hojas y hojitas retocadas; predominio claro de las especies domésticas sobre las silvestres; $\mathrm{y}$, dentro del geometrismo, de las formas trapezoidales y del retoque abrupto. Su correspondencia con el Complejo Neolítico de la secuencia clásica es evidente.

Además de los utilizados en el análisis, se relacionarían con este grupo otros conjuntos del Mediterráneo peninsular. La información que podría añadirse a partir de estos últimos no desdice la proporcionada por los primeros, por lo que nos basaremos solamente en estos últimos. Las fechas C-14 disponibles son:

Plansallosa $5890 \pm 80 \mathrm{BP}$

Chaves IIa $6280 \pm 70 \mathrm{BP}$; $6170 \pm 70 \mathrm{BP}$

Chaves IIb $6820 \pm 70 \mathrm{BP} ; 6700 \pm 80 \mathrm{BP}$ $6510 \pm 70 \mathrm{BP} ; 5260 \pm 340 \mathrm{BP}$

$\begin{array}{ll}\text { Or III } & 6770 \pm 370 \mathrm{BP} ; 6680 \pm 290 \mathrm{BP} \\ \text { Or II } & 6030 \pm 270 \mathrm{BP} \\ \text { Or S/R } & 6650 \pm 160 \mathrm{BP} ; 6315 \pm 75 \mathrm{BP} \\ \text { Jovades } & 4810 \pm 60 \mathrm{BP} ; 4660 \pm 90 \mathrm{BP} \\ & 4370 \pm 60 \mathrm{BP}\end{array}$

Como puede verse, estas dataciones indican una larga perduración del Complejo Neolítico sin grandes transformaciones en las variables estudiadas. No quiere ello decir que tales cam- bios no se manifiesten en otros aspectos, pero dado que nuestro propósito consistía en aislar el componente técnico asociado al económico que definiera el Complejo Neolítico, tales cuestiones carecían de relevancia.

En su conjunto, esta situación refleja bastante bien lo esperado de acuerdo con la hipótesis dual de la aculturación directa. Desde esta perspectiva, los grupos 1 a 3 corresponderían a la Fase 0 del modelo (precerámica); los G.4 y 5 y los G.7 y 8, en sus horizontes más antiguos, a la Fase 1; mientras que G.6 y parte de G7 y G8 (Jovades) se situarían en la fase 2.

'La ruptura ocupacional, prevista por el modelo para la Fase 1, debiera observarse entre los asentamientos de los G.4 y G.5, por un lado, y G.7 y 8 por otro. Así, mientras los primeros tenderían a mostrar una fuerte correlación (continuidád en la ocupación de los sitios) con los ocupados durante la Fase 0, lo contrario debería observarse entre los del grupos 7 y 8 (Cuadro 4).

\begin{tabular}{|cccc|}
\hline & Fase 0 & Fase 1 & Total \\
\hline G.4+5 & 5 & 5 & 5 \\
G.7+8 & 0 & 6 & 6 \\
\hline
\end{tabular}

Cuadro 4. Yacimientos de los grupos 4/5 y 7/8 con niveles atribuibles a la Fase 0, precerámica. Puede verse la estrecha relación de los yacimientos del grupo $4 / 5$ con la Fase 0 . Lo contrario ocurre con los yacimientos del grupo $7 / 8$, ninguno de los cuales presenta niveles relacionables con la Fase 0.

En suma, los resultados anteriores parecen demostar que la neolitización se realizó en este región de acuerdo con la hipótesis de la aculturación directa, es decir, como consecuencia de la interacción entre los grupos de agricultores y ganaderos en expansión (G.7 y 8) y los representantes del Mesolítico final regional (G.1 a 3).

Al principio (G.4), las innovaciones aceptadas entre los grupos mesolíticos son más técnicas (cerámica) que económicas. La ausencia -o la muy escasa incidencia- de los recursos domésticos así lo atestigua. La aceptación de estos últimos pretende, en última instancia, salvaguardar el sistema de subsistencia tradicional, 

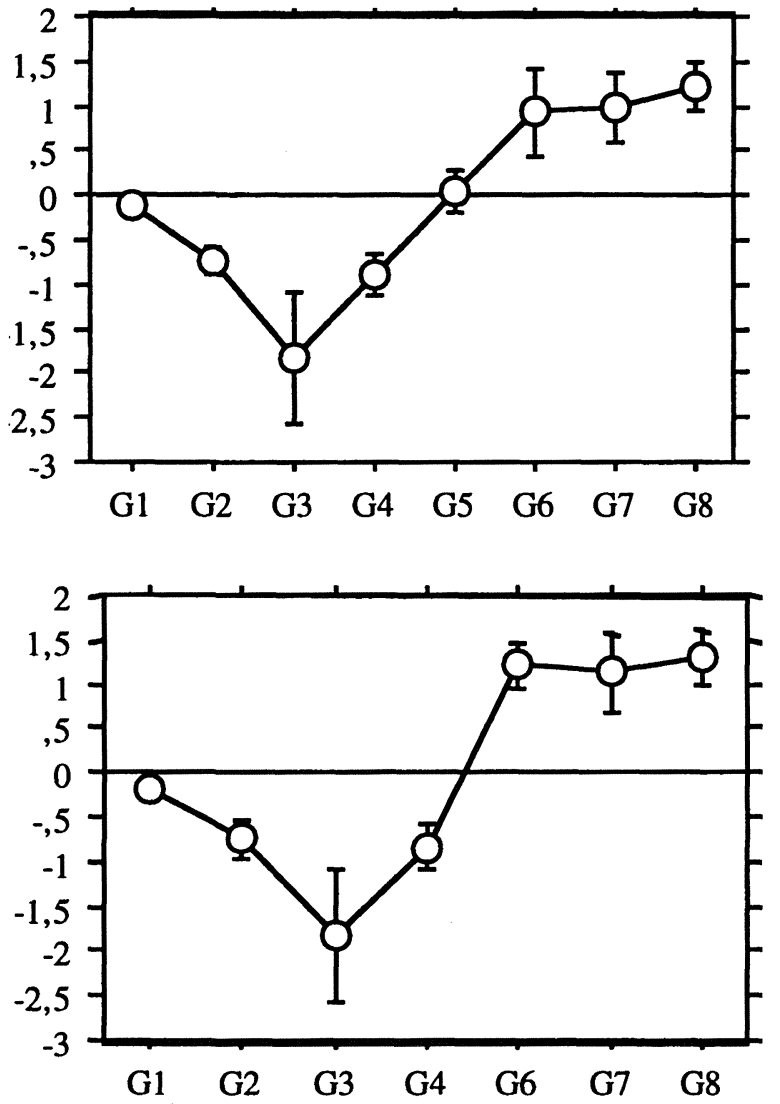

Fig. 3. Media y desviación estándar para los distintos grupos en el factor 1. Arriba, con todos los conjuntos; abajo, sólo conjunto con $\mathrm{n}>80$. Los valores positivos de $\mathrm{G}$. 6,7 y 8 evidencian elevadas proporciones en las varibles Ilre y Dom. Son los conjuntos que pueden considerarse neolíticos técnica y económicamente

antes que cambiarlo. Por esta razón debiéramos esperar que la incorporación de los recursos domésticos se realice siguiendo las mismas pautas de gestión aplicadas a los recursos silvestres. La comprobación de este extremo no es fácil, pero la investigación sobre los patrones de sacrificio o las marcas de carnicería indicativas de patrones de consumo (Pérez Ripoll, 1992; Aura y Pérez Ripoll, 1995) pueden constituirse en vías de investigación adecuadas para ello.

Las evidencias actuales indican que el final del proceso debe relacionarse con el grupo 6. Con todo, no debemos olvidar la posibilidad de que esta imagen sea resultado de la confluencia de situaciones distintas, de acuerdo con lo estipulado en el supuesto 5 del modelo (ver apartado 3 ).

\section{DISCUSIÓN}

Como se ha reflejado más arriba, el carácter técnico y económico del Complejo Neolítico viene medido, respectivamente, por las variables Ilre y Dom. Ambas aparecen asociadas con altos valores positivos en el factor 1 . En función de ello, los asentamientos se organizan en dos grandes bloques (Fig. 3):

- Los grupos 1 a 4 (ó 5), caracterizados por la nula o escasa relevancia de estas variables.

- Los grupos 6, 7 y 8, caracterizados por la situación opuesta.

Si la neolitización se hubiese producido mediante la asimilación progresiva de las novedades técnico-económicas, sin participación en el proceso de grupos alóctonos, entonces cabría esperar que los yacimientos plenamente' neolíticos de esta región fueran más recientes. En otras palabras, que los G.6, 7 y 8 fueran cronológicamente posteriores a los $\mathrm{G} .1$ a 4 (y G.5), con independencia de cualquier otra característica u organización interna de los mismos.

Aunque el número de dataciones es todavía escaso, basta para darnos cuenta de que esta situación no encuentra apoyo empírico, lo que invalida la hipótesis de la aculturación indirecta formulada en su forma más simple.

Sin embargo, recientemente se han propuesto otras alternativas que tratan de explicar la dualidad observada sin recurrir a la expansión demográfica.

Barandiarán y Cava (1992) sugieren que la asimilación progresiva de los nuevos elementos neolíticos conllevaría una especialización funcional/estacional entre los asentamientos. Esta sugerencia ha sido retomada por Vicent (1996) integrándola en su propuesta del modelo de capilaridad, que a su vez deriva del modelo del filtro (Lewthwaite, 1986). Con independencia de los detalles concretos, el modelo de capilaridad asume una situación relativamente estática de la población, suponiendo que lo que se mueve es la información. Y, aunque no excluye la posibilidad de los procesos de expansión démica, elimina la dependencia de dichos procesos en las explicaciones relativas a los fenómenos de transmisión de información. Sobre esta asunción de partida, Rodrí- 
guez Alcalde et alii (1995) han elaborado una propuesta que aplican al conjunto del Mediterráneo utilizando determinados elementos de la teoría del caos.

En este contexto, debe tenerse en cuenta que la interpretación funcional/estacional antes aludida, para que pueda ser alternativa, debe darse en el seno de subsistencias no neolíticas.

Así, la plena dependencia agrícola conlleva sistemas de explotación del medio definidos por la constitución de equipos de trabajo estables, ligados al medio de producción y al producto almacenado, necesario tanto para la reproducción de la fuerza de trabajo como para la repetición del ciclo agrícola. Estabilidad y sedentarización (ausencia de ciclos estacionales) son características de este sistema. Sólo el componente ganadero está sujeto a cierta movilidad estacional. Pero no es ésta la estacionalidad que se propugna, dado que si así fuera, necesariamente deberíamos admitir la existencia de un sistema plenamente neolítico desde el inicio de la secuencia cerámica, lo que rompería el principio de progresividad que subyace detrás de esta propuesta.

En efecto, con independencia de otras consideraciones, la diferencia básica entre los modelos de aculturación indirecta (que no suponen movimiento de población), y los de aculturación directa (caso contrario), reside en el cumplimiento de lo que podríamos denominar la premisa de la doble progresividad:

a) Progresividad en la adquisición de los diferentes elementos tecno económicos del Neolítico. Esta exigencia simplemente establece que la aparición de estos elementos, tomados aisladamente, tendrá un claro gradiente cronológico, siendo tanto más reciente cuanto más alejado (o inconexo) del centro originario se encuentre un determinado asentamiento. Esta premisa obliga a ambas clases de modelos.

b) Progresividad en la aparición de sistemas plenamente neolíticos. Ello significa que, en una región dada, la aparición de los elementos tecno-económicos novedosos precederá a la constitución de sistemas plenamente neolíticos. Esta premisa sólo obliga a aquellos modelos que suponen un movimiento de información; por el contrario, los que implican expansión demográ- fica necesariamente han de suponer una colonización agrícola, lo que paralelamente conlleva el establecimiento de sistemas agrícolas plenos.

En relación al contexto que nos ocupa, la asunción de un modelo que no implique movimientos de población vendría a significar que los asentamientos identificados en nuestros grupos 7 y 8 , no representan una plena dependencia agrícola ni, por tanto, una vida aldeana asociada a la misma (de ahí que puedan considerarse como especializaciones funcionales/estacionales con respecto a los grupos 4 y 5). Consecuentemente, no existiría la dualidad económica prevista por el modelo dual y la aparición de los sistemas neolíticos sería progresiva en el tiempo. Éste es el punto esencial en toda esta discusión, pero ¿cómo proceder a su contrastación?

Una forma de enfocar este problema consiste en evaluar el grado de dependencia de los recursos domésticos que muestran estos grupos, junto con la presencia asociada de los poblados al aire libre.

Por lo que respecta a los recursos animales, ya se ha puesto de manifiesto en el análisis la alta participación de las especies domésticas en todos los conjuntos de los grupos 7 y 8 , cuya proporción media se sitúa en torno al 0,75.

En lo que se refiere a la agricultura, los recientes trabajos realizados en los yacimientos de La Draga o la Cova de les Cendres (Buxó, 1991 y 1993) vienen a confirmar la plena dependencia agrícola en un doble sentido:

- Documentando la presencia de grandes concentraciones de cereales, generalmente asociadas a lugares de almacén, tanto en cuevas (Or), como en poblados (La Draga).

- Indicando el predominio claro de las especies domésticas. Éste es el caso de la Cova de les Cendres (yacimiento no incluido en el análisis a falta de los datos detallados de la fauna), donde la proporción de semillas domésticas dispersas por el sedimento alcanza el $0,97 \mathrm{del}$ total de las recuperadas, de las cuales el 0,09 corresponde a legumbres domésticas.

Con esta situación tan claramente dominada por los recursos domésticos, resultaría extraño que no se documentase un buen número de asentamientos al aire libre correspondientes al Neolítico antiguo. En realidad, la ausencia de este 
apartado en la documentación arqueológica de hace tan sólo una década parecía una consecuencia del sesgo de la investigación en favor de aquellos asentamientos más fácilmente visibles en el paisaje arqueológico (Bernabeu y Martí, 1992).

En consecuencia, cuando tras los primeros hallazgos más o menos fortuitos, se han iniciado programas de actuación sistemática sobre territorios delimitados, el resultado consiste en un aumento considerable de los asentamientos (poblados) atribuibles al Neolítico antiguo. Así, a los hallazgos catalanes (Mestres, 1991; Bosch et alii, 1991; Alcalde et alii, 1992; Bosch, 1994), se han de añadir los recientes descubrimientos en las comarcas centrales del País Valenciano, donde asentamientos como Mas d'Is (aún inédito), documentan una ocupación continuada entre el VII y el V milenio BP a juzgar por los materiales superficiales recogidos (cerámicas cardiales, incisas, esgrafiadas, peinadas y dientes de hoz).

Los trabajos de excavación se encuentran, en la mayoría de los casos, inéditos o con publicaciones preliminares, de manera que no permiten definir la estructuración interna del espacio en estos asentamientos, pero cuando menos permiten afirmar que el corolario de la plena dependencia agrícola, la vida aldeana, no era desconocida durante el primer Neolítico.

En resumen, la evidencia empírica disponible no permite corroborar la tesis de la progresividad en la aparición de los sistemas neolíticos. Por tanto, los modelos que implican una estabilidad de la población y una fluidez de la información no pueden pretender explicar el proceso de neolitización, al menos si se postulan de forma exclusiva. Consecuentemente, la propuesta de la especialización funcional/estacional debe rechazarse.

\section{RECAPITULACIÓN. NEOLITIZACIÓN Y TERRITORIO}

$\mathrm{Al}$ comienzo de este trabajo comentábamos cómo el modelo dual pretendía superar la bipolaridad entre los enfoques indigenistas y migracionistas, presentando una fomulación según la cual ambos procesos no sólo podían darse juntos, sino que prácticamente se complementaban. Ello viene a significar, entre otras cosas, que es

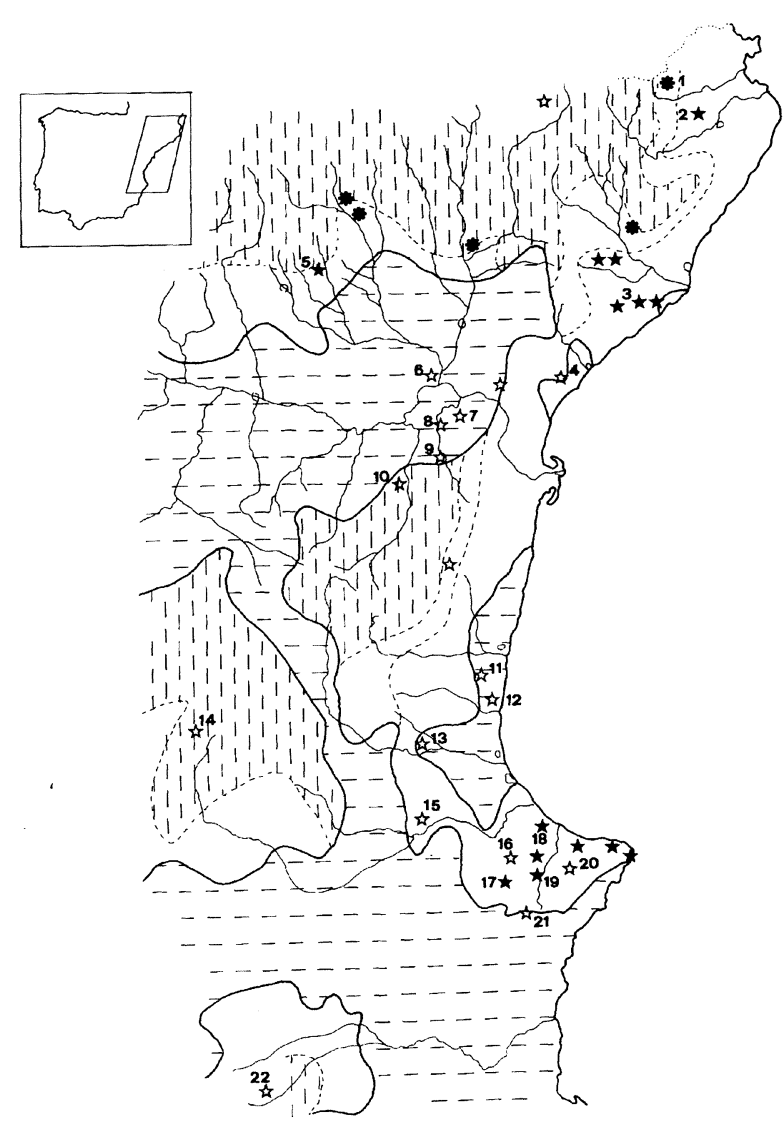

Fig. 4. Región mediterránea española con indicación de las áreas óptimas y marginales desde el punto de vista agrícola. Las estrellas huecas se corresponden con asentamientos del Complejo Geométrico; las estrellas negras, con los asentamientos del Complejo $\mathrm{Ne}$ olítico (Horizonte Cardial clásico; primera mitad VII milenio BP); los puntos negros aserrados, con aquellos otros situables en la segunda mitad del VII milenio BP. Además de los asentamientos utilizados en este trabajo (que aparecen numerados), se han incluido otros sobre los que existe cierto consenso en su correcta atribución cultural.

Regiones óptimas, definidas por la isoyeta de $500 \mathrm{~mm}^{3}$, en trazo grueso. En trazo discontinuo se señalan los isotermas de $4^{\circ}$ y $6^{\circ} \mathrm{C}$.

Regiones marginales, con precipitacones inferiores a $500 \mathrm{~mm}^{3}$.

III Regiones marginales, con temperaturas inferiores a $4^{\circ} \mathrm{C}$.

posible esperar un comportamiento territorial en los diferentes procesos de neolitización.

Si fuéramos capaces de aislar las variables adecuadas, estos diferentes comportamientos podrían trasladarse con relativa comodidad sobre un plano. Lo que sigue constituye un pri- 
mer intento, cuyos resultados, aunque preliminares, parecen indicar que un enfoque de esta clase puede ser adecuado.

Considerando que la elección del territorio se realizaría sobre todo atendiendo a un criterio de subsistencia y, en especial, tratando de minimizar el riesgo en la agricultura, se ha supuesto que las áreas más favorables para la instalación de los primeros colonos serían aquéllas con suelos altamente productivos, que conserven bien la humedad, con una precipitación anual superior a $500 \mathrm{~mm}^{3}$ y escaso riesgo de heladas fuera de los meses invernales. En esta primera aproximación he utilizado solamente las dos últimas variables, la última medida de forma indirecta como la temperatura media del mes más frío, fijando su límite inferior en $4^{\circ} \mathrm{C}$.

La combinación de ambas definirá las regiones óptimas para la instalación de una agricultura de escasa inversión y elevado rendimiento, donde es de esperar se encuentren los asentamientos del Complejo Neolítico más antiguos. Progresivamente, la colonización agrícola penetrará regiones cada vez más marginales.

Por contra, los asentamientos del Complejo Geométrico tenderán a distribuirse aleatoriamente, tanto entre las áreas óptimas como en las agrícolamente marginales. La coincidencia de ambos grupos sobre algunas de las regiones óptimas, o en sus límites, constituirá la zona de fronteras iniciales. Ésta actuará como un filtro a través del cual aquellos grupos situados más allá conocerán y asimilarán, adaptándolas a sus propias necesidades, las novedades tecnoeconómicas del Neolítico.

Si dispusiéramos de una foto fija de la situación en torno al $6500 \mathrm{BP}$, la imagen debería asemejarse bastante a un mosaico, donde las regiones con vestigios de colonización aparecerán limitadas por otras donde se documentará la presencia de grupos mesolíticos. A medida que nos alejemos de los núcleos iniciales, este mosaico tenderá a ser sustituido por una tapiz uniforme de grupos mesolíticos diferenciados por la presencia/ausencia de los nuevos elementos neolíticos en función de su distancia respecto de los centros de colonización agrícola inicial.

Aunque expresada en forma manifiestamente mejorable (escala demasiado grande) la figura 4 sugiere una buena correlación entre la evidencia empírica disponible y las anteriores previsiones, de manera que:

a) Unas regiones, situadas en las áreas óptimas, asisten a un proceso de neolitización basado en la progresiva expansión del poblamiento de los grupos de agricultores y ganaderos instalados en la región. Nos encontramos ante el territorio de la colonización.

A título de ejemplo, y sin pretender ser exhaustivo, con la información disponible sería posible diferenciar dos núcleos iniciales dentro de la región mediterránea cuyas características se avendrían bien con un modelo de colonización: las comarcas litorales o prelitorales catalanas centradas en torno al curso medio-bajo del Llobregat y las comarcas litorales y prelitorales valencianas centradas en torno al curso del río Alcoi o Serpis, donde se localizan los clásicos yacimientos de Or y Sarsa.

Ambas presentan una característica común: el evidente impacto de lo cardial. Probablemente, se podría afirmar sin exageración que ambas concentran la gran mayoría de las cerámicas cardiales de todo el territorio. Es posible que no sean éstos los únicos núcleos iniciales, pero no parece que puedan rastrearse muchos más. En ambas latitudes y con un lapso de tiempo que las dataciones C-14 y los conjuntos materiales dejan suponer rápido, aparecen otros situados más al interior, como los de las comarcas oscenses (Baldellou, 1987) o granadinas (Navarrete y Molina, 1987).

b) En sus límites, las fronteras definirán las regiones de contacto con los grupos mesolíticos, conformando el territorio estricto de la hipótesis dual.

La interacción entre éstos y los grupos neolíticos provocará, a lo largo de un lapso de tiempo difícil de determinar, un proceso de neolitización que, a grandes rasgos, vendría caracterizado en los siguientes términos:

- Aceptación y difusión rápida de los elementos técnicos, como la cerámica.

- La incorporación de los recursos domésticos refleja una mayor parsimonia. Excepción hecha del caso de Cocina, el resto de las estratigrafías o bien no proporcionan información, o muestran una escasa relevancia de los recursos domésticos hasta momentos cercanos al 5500

T. P., 53, n. ${ }^{\circ} 2,1996$ 
BP. Es posible que esta situación resulte del todavía escaso nivel de información disponible. Así, por ejemplo, de confirmarse las impresiones inciales del yacimiento de Riols (Royo y Gómez, 1992), la fecha anterior podría retrotraerse hasta $c a .6000 \mathrm{BP}$. En este aspecto los datos no son concluyentes.

c) Más allá de las fronteras, las redes sociales y económicas existentes entre los grupos mesolíticos serán las responsables de la difusión de los nuevos elementos. Nos encontramos ante el territorio de modelos como el de la capilaridad.

Si las situaciones de colonización y de aculturación directa son visibles, como acabamos de ver, en algunas partes de la región mediterránea española, la aculturación indirecta se perfila claramente como un fenómeno mayoritario tanto en esta región como en aquellas otras situadas más al interior. Sería el caso de la cuenca del Ebro, donde las estratigrafías conocidas parecen abogar por una clara progresividad en la aparición de los sistemas neolíticos (Cava, 1986; García Gazólaz, 1993). Una situación similar, aunque dentro de un ambiente no mediterráneo, parece observarse en el Cantábrico (Arias, 1991).

El corolario de esta situación resulta, creo, evidente: la neolitización de la Península Ibérica no fue un proceso uniforme, sino diverso y complejo. Complejidad que parece capaz de cobijar por igual tanto los planteamientos indigenistas como los colonialistas.

Tal vez modelos como el de la geometría fractal podrían hacer frente a su descripción, no sólo con mayor elegancia, sino con mayor realismo que el del frente de avance, a condición, sin embargo, de que sean capaces de incluir en su planteamiento y desarrollo no sólo el movimiento de información, sino también de poblaciones que, como acabamos de ver, posee un componente territorial y no aleatorio.

\section{BIBLIOGRAFÍA}

ARIAS, P. (1991): "De cazadores a campesinos. La transición al Neolítico en la región cantábrica”. Universidad de Cantabria.

Ammerman, A.J. y Cavalli-Sforza, L.L. (1984): "The neolithic transition and the genetics of population in Europe". Princeton University Press.
ANFruns, J. y Llobet, E. (eds.) (1990): “El canvi cultural a la Prehistòria”. Ed. Columna. Barcelona.

Asquerino, M.D. y LóPEZ, P. (1981): "La cueva del Nacimiento (Pontones): un yacimiento Neolítico en la sierra del Segura". Trabajos de Prehistoria, 38: 109-152.

Aura, J.E. y PÉrez RIPOLl, M. (1995): "El Holoceno inicial en el mediterráneo español (11.000-7.000BP). Características culturales y económicas”. En V. Villaverde (ed.): 119-146.

BALDELlou, V. (1987): "Los orígenes de la agricultura en el Alto Aragón". En J. Guilaine et alii (eds.): 621-626.

BALDEllou, V. y Utrilla, P. (1985): "Nuevas dataciones de radiocarbono de la prehistoria oscense". Trabajos de Prehistoria, 42: 83-95.

BARANDIARÁN, I. (1978): "El abrigo de Botiquería dels Moros. Mazaleón (Teruel). Excavaciones arqueológicas de 1974”. Cuadernos de Prehistoria y Arqueología Castellonense, 5: 49-138.

BARANDIARÁN, I. y CAVA, A. (1989): La ocupación prehistórica del abrigo de Costalena (Maella, Zaragoza). Cuadernos de Arqueología y Paleontología, 6. Diputación General de Aragón.

- (1992): "Caracteres industriales del Epipaleolítico y Neolítico en Aragón: su referencia a los yacimientos levantinos". En Aragón/Litoral mediterráneo. Relaciones culturales durante la Prehistoria. Actas del coloquio. Zaragoza, 1989: 181-196. Institución Fernando el Católico. Zaragoza.

Barton, M.; Rubio, F.; Miksicek, CH.A. y Donahue, D.J. (1990): "Domestic Olive". Nature, 346: 518-519.

BenAvente, A. y ANDrÉs, M.T. (1988): "El yacimiento neolítico de Alonso Norte (Alcañiz, Teruel). Memoria de las prospecciones y excavaciones arqueológicas de 1984-85". Al-Qannis, 1: 2-58.

BERnABEU, J. (1989): La tradición cultural de las cerámicas impresas en la zona oriental de la Península Ibérica. Trabajos Varios del Servicio de Investigación Prehistórica, 86. Diputación Provincial. Valencia.

- (dir.) (1993): "El III milenio a.C. en el País Valenciano. Los poblados de Jovades (Cocentaina, Alacant) y Arenal de la Costa (Ontinyent, València)". Saguntum (PLAV), 26: 9-180. Universitat de València.

Bernabeu, J., Aura, J.E. y Badal, E. (1993): “Al oeste del Edén. Las primeras sociedades agrícolas en la Europa mediterránea". Ed. Síntesis. Madrid.

Bernabeu, J. y Juan Cabanilles, J. (e.p.): "Le Néolithique au Pays Valencienne". Comunicación presentada al XXIV Congrès Préhistorique de France. Carcassonne, septiembre de 1994.

Bernabeu, J. y Martí, B. (1992): "El País Valenciano de la aparición del Neolítico al Horizonte Campaniforme”. En Aragón/Litoral mediterráneo. Relaciones culturales durante la Prehistoria: Actas del Coloquio. Zaragoza, 1989: 213-234. Institución Fernando el Católico. Zaragoza.

Bosch J.; Miró, J.M. y Molist, M. (1991): "El marc històric $\mathrm{i}$ arqueològic dels origens de l'agricultura a Catalunya". Cota Zero, 7: 77-87. Barcelona.

BosCH LlORET, A. (1994): "El Neolítico antiguo en el nordeste de Cataluña. Contribución a la problemática de

T. P., 53, n. ${ }^{\circ} 2,1996$ 
la evolución de las primeras comunidades neolíticas en el Mediterráneo occidental". Trabajos de Prehistoria, 51(1): 55-76.

Buxó, R. (1991): "Nuevos datos de investigación de restos paleocarpológicos: algunos aspectos sobre la presencia de leguminosas en el mediterráneo peninsular". En A. Vila (coord.): “Arqueología”. Col. Nuevas tendencias, C.S.I.C. Madrid: 101-114.

- (1993): "Des semences et des fruits. Cueillette et agriculture en France et en Espagne méditerranéennes du Néolithique a l'Âge du Fer". Tesis doctoral inédita. Université Sciences et Techniques du Languedoc, Montpellier II.

CACHO, C. (1988): “Tossal de la Roca, Vall d'Alcalà”. Memòries arqueològiques a la Comunitat Valenciana, 1984-1985: 105-111. Generalitat Valenciana.

CAva, A. (1983): "La industria lítica de Chaves". Bolskan, 1: $95-109$.

- (1986): "La industria lítica de la prehistoria reciente en la cuenca del Ebro". Boletín del Museo de Zaragoza, 5: 19-75.

Chapman, J. (1994): "The Origins of Farming in South East Europe". Préhistoire Européenne, 6: 133-156.

DENNELL, R. (1985): "The hunther-gatherer/agricultural frontier in temperate Europe". En S.W. Green y S.M. Perlman (eds.): $113-140$.

FORTEA, J. (1973): "Los complejos microlaminares y geométricos del Epipaleolítico mediterráneo español”. Universidad de Salamanca. Salamanca.

- (1975): "Tipología, hábitat y cronología relativa del Estany Gran de Almenara". Cuadernos de Prehistoria y Arqueología Castellonense, 2: 22-38.

FORTEA, J. y MARTí, B. (1985): "Consideraciones sobre los inicios del Neolítico en el Mediterráneo español". Zephyrus, XXXVII-XXXVIII: 167-199. Universidad de Salamanca.

Fortea, J.; Martí, B.; Fumanal, M.P.; Dupré, M. y Pérez Ripoll, M. (1987)a: "Epipaleolítico y neolitización en la zona oriental de la Península Ibérica". En Guilaine et alii (eds.): 581-591.

Fortea, J.; Martí, B. y Juan Cabanilles, J. (1987)b: "L'industrie lithique du Néolithique ancien dans la versant méditerranéen de la Peninsule Ibérique". En "Chipped stone industries of the early farming cultures in Europe" (Actas del Coloquio de Cracovia). Archeologia Interregionalis: 521-542. Kracovia.

Gallay, A. (1989): "La place des Alpes dans la néolithisation de l'Europe". En O. Aurenche y J. Cauvin (eds.): Néolithisations. British Archaeological Repports, International Series, 516: 227-254.

GaRCía GAZÓlaz, J. (1995): "Apuntes para la comprensión de la dinámica de ocupación del actual territorio navarro entre el VI y el III milenio". Cuadernos de Arqueología de la Universidad de Navarra, 3: 85-146.

Green, S.W. y Perlman, S.M. (eds.) (1985): "The Archaeology of frontiers and boundaries". Academic Press.

Guilaine, J.; Courtin, J.; Roudil, J.L. y Vernet, J.L. (eds.) (1987): "Premières communautés Paysannes en Méditerranée Occidentale". Actas del Coloquio internacional de Montpellier (1983). CNRS París.
Juan Cabanilles, J. (1984): "El utillaje neolítico en sílex del litoral mediterráneo peninsular". Saguntum (PLAV), 18: 49-102. Universitat de Valencia.

- (1985): "El complejo Epipaleolítico Geométrico (facies Cocina) y sus relaciones con el Neolítico Antiguo". Saguntum (PLAV), 19: 9-30. Universitat de Valencia.

- (1990): "Substrat epipaléolithique et néolithisation en Espagne: l'apport des industries lithiques à l'identification des traditions culturelles". En Cardial et Rubane, Actas del Coloquio de Lieja. ERAUL, 39: 417435.

- (1992): "La neolitización de la vertiente mediterránea peninsular. Modelos y problemas". En Aragón/Litoral mediterráneo. Relaciones culturales durante la Prehistoriá. Actas del Coloquio de Zaragoza, 1989: 255-268. Institución Fernando el Católico. Zaragoza.

LEwTHWAite, J. (1986): "The transition to food production: a mediterranean perspective". En M. Zvelebil (ed.): "Hunters in transition". Cambridge University Press. Cambridge: 53-66.

MARTí, B. (1980): Cova de l'Or (Beniarrés, Alicante). Vol. II. Trabajos Varios del Servicio de Investigación Prehistórica, 65. Diputación Provincial. Valencia.

Martí, B.; Fortea, J.; Bernabeu, J.; Pérez Ripoll, M.; ACuÑA, J.D.; Robles, F. y Gallart, M.D. (1987): “El Neolítico antiguo en la zona oriental de la Península Ibérica". En J. Guilaine et alii (eds.): 607-620.

MAZO, C. y MonTES, L. (1992): "La transición Epipaleolítico-Neolítico antiguo en el abrigo de El Pontet (Maella, Zaragoza)". En Aragón/Litoral mediterráneo. Relaciones culturales durante la Prehistoria. Actas del Coloquio. Zaragoza, 1989: 243-254. Institución Fernando el Católico. Zaragoza.

Mestres, J. (1987): "La indústria lítica en sílex del Neolitic Antic a les Guixeres de Vilobí". Olerdulae, XII: 572.

- (1992): “Assentaments a l'aire lliure del Neolitic antic al Penedès. Estat de la investigació del Neolitic a Catalunya". En Estat de la Investigació sobre rel Neolitic a Catalunya. 9è. col.loqui internacional d'Arqueologia de Puigcerdà (Puigcerdà i Andorra, 1991). 76-78. Andorra.

Miró, J.M. (1996): “Continuidad o ruptura entre los tecnocomplejos líticos del VI al V milenio BC: la contribución de las industrias líticas del V milenio BC de la Catalunya meridional". I Congreso de Neolítico en la Península Ibérica (Gavà, 1995). Rubricatum, 1, 1: 139-150.

Miró, J.M. y BosCH, J. (1990): "El procés de neolitització a Catalunya”. En J. Anfruns y E. Llobet (eds.): 295-330.

Moore, J.A. (1985): "Forager/Farmer interactions: information, social organisation and the frontier". En S.W. Green y S.M. Perlman (eds.): 93-112.

Moure, J.A. y Fernández MirandA, M. (1976): "El abrigo de Verdelpino (Cuenca). Noticia de los trabajos de 1976". Trabajos de Prehistoria, 34: 31-83.

Navarrete, M.S. y Molina, F. (1987): "Le processus de néolithisation et le début de la sédentarisation en Haut Andalousie". En J. Guilaine et alii (eds.): 645-652.

NoceTe, F. (1989): El Espacio de la Coerción. La Transición al Estado en las Campiñas del Alto Guadalquivir 
(España). 3000-1500 a.C. British Archaeological Repports, International Series, 492.

Pérez Ripoll, M. (1992): Marcas de carnicería, fracturas intencionadas y mordeduras de carnívoros en huesos prehistóricos del mediterráneo español. Instituto de Cultura Juan Gil-Albert. Colección Patrimonio, 15. Alicante.

Perlés, C. (1995): "La transition Pléistocène/Holocène et le problème du Mésolithique en Grèce". En V. Villaverde (ed.): 179-209.

Rodríguez Alcalde, A.; Alonso Jiménez, C. y VeláZquez CANO, J. (1995): "Fractales para la arqueología: un nuevo lenguaje". Trabajos de Prehistoria, 52(1): 13-24.

Royo, J.I. y GómEZ, F. (1992): "Un asentamiento Neolítico al aire libre en la confluencia de los ríos Segre y Ebro". En Aragón/Litoral Mediterráneo: intercambios culturales durante la Prehistoria. Actas del Coloquio. Zaragoza, 1989. 297-308. Institución Fernando el Católico. Zaragoza.

RunNels, C. y VAN Andels, T.H. (1988): "Trade and the origins of the agriculture in the Near East and South
East Europe". Journal of Mediterranean Archaeology, 1: 83-109.

Schuhmacher, T.X. y Weniger, G.C. (1995): "Continuidad y cambio. Problemas de la neolitización en el Este de la Península Ibérica". Trabajos de Prehistoria, 52(2): 83-98.

VICENT, J.M (1990): "El Neolitic. Transformacions socials i econòmiques". En J. Anfruns y E. Llobet (eds.): 241-293.

- (1996): "The 'insular filter' hypothesis revisited". En M.S. Balmouth, A. Gilman y L. Prados Torreira (eds.): Encounters and Transformations. The Archaeology of Iberia in Transition. Monograhps in Mediterranean Archaeology, 7. Plenum.

VillaVERde, V. (ed.) (1995): “Los últimos cazadores. Transformaciones culturales y económicas durante el Tardiglaciar y el inicio del Holoceno en el ámbito mediterráneo". Instituto de Cultura Juan Gil-Albert. Alicante.

Wolf, E.R. (1971): "Los campesinos". Ed. Labor. Barcelona.

ZVELEBIL, M. y Rowley-Conwy, P. (1984): "Transition to farming in northern Europe: a hunther-gatherer perspective". Norwegian Archaeological Review, 17/2: 104-128. 